\title{
71. Some Properties and N-Terminal Sequence of Plastocyanin of the Carrot, Daucus carota*)
}

\author{
By Yasutomo Sugimura, Tadashi Hoshino,**) \\ Akihiko KaRaHashi,***) Fuminori YoshIZaKI, \\ and Masami SHIMoKoRIYAMA \\ Department of Biology, Faculty of Science, Toho University, \\ Funabashi, Chiba 274 \\ (Communicated by Noburô KamiYa, M. J. A., Nov. 12, 1983)
}

Plastocyanin, a copper protein, was first isolated by Katoh in 1960 from the green alga, Chlorella ellipsoidea, and subsequently from various higher plants. ${ }^{1,2)}$ The protein is present in the chloroplasts and functions as an electron carrier from cytochrome $f$ to P700 in the electron transport chain between photosystem II and I. ${ }^{3)}$ The redox reaction of plastocyanin is due to its copper valency change $\mathrm{Cu}^{++}+\mathrm{e} \rightleftharpoons \mathrm{Cu}^{+}$. The cupric form shows a characteristic absorption band around $597 \mathrm{~nm}$ and two broad bands around 460 and $775 \mathrm{~nm}$ so that the color is bright blue. The cuprous form does not show any visible absorption. Plastocyanin is not autoxidizable and has a high midpoint redox potential. of 0.37 volt. ${ }^{4}$

Structural analysis of plastocyanin indicates that this protein with about 10,000 molecular weight consists of single polypeptide chain of 98-105 amino acid residues and one copper atom.5) The amino acid sequence of the protein from several higher plants has been investigated from a view point of molecular evolution.5) Recently, the three dimensional structure has been determined for the poplar plastocyanin by its X-ray analysis to be able to discuss about its inner-molecular mechanism of the electron transport activity of the protein. ${ }^{6)}$

We have been interested in comparative studies of the relationship between the physiological function and chemical properties or the structure, and molecular phylogeny of the photosynthetic electron carrier proteins, namely, algal cytochrome $c_{6}$ and its analogous protein, plastocyanin..$^{7-9)}$ In this communication we wish to describe

*) This work was supported in part by Grant-in-Aid for Special Project Research (no. 58112004) from the Ministry of Education, Science and Culture of Japan.

**) Present Address: Byotai-Seiri Institute, Itabashi, Tokyo.

***) Present Address: Kogane Lower Secondary School, Matsudo, Chiba. 
the extraction, purification, some physico-chemical properties, and $\mathrm{N}$-terminal sequence of plastocyanin of the leaves of the carrot, Daucus carota, of Apiaceae.

Materials and methods. The green leaves of the carrot, $D$. carota, were obtained from May to June from a farmer in Funabashi, Chiba. The leaves were picked, washed with tap water and stocked in a freezer at $-20^{\circ} \mathrm{C}$ before use. Hydroxyapatite was prepared according to Main et al. ${ }^{10)}$ The extraction of plastocyanin was performed by thawing and homogenizing the frozen leaves $(3 \mathrm{~kg})$ with $\mathrm{K}_{2} \mathrm{HPO}_{4}(52 \mathrm{~g})$ and $\mathrm{KH}_{2} \mathrm{PO}_{4}(28 \mathrm{~g})$. The crude extract was treated with acrinol and fractionated with ammonium sulfate between the 0.4 and 1.0 saturation. The further purification was carried out by DEAE-cellulose, DEAE-Sephadex A-25, hydroxyapatite and Sephadex G-75 gel filtration column chromatographies. The purity of the preparation was checked by a polyacrylamide disc gel electrophoresis. ${ }^{11)}$ The amount of plastocyanin was determined spectrophotometrically at $597 \mathrm{~nm}$ using an extinction coefficient of $4.7 \mathrm{mM}^{-1} \cdot \mathrm{cm}^{-1}$ described below.

Absorption spectra were measured in a Hitachi 139 and 200 spectrophotometer. Cupriplastocyanin solution was prepared by dialysis against $50 \mu \mathrm{M} \mathrm{K}$-ferricyanide solution; cuproplastocyanin was obtained by adding a minute amount of ascorbic acid to the cupriplastocyanin solution. The midpoint redox potential of plastocyanin was determined by equilibrium with a ferro- and ferricyanide system with a midpoint redox potential of 0.418 volt. ${ }^{12)-14)}$ The redox change of plastocyanin was followed at $597 \mathrm{~nm}$. The molecular weight of plastocyanin was estimated by gel filtration on a Sephadex G-75 column. ${ }^{7}$ The minimum molecular weight and molar extinction coefficient at $597 \mathrm{~nm}$ of plastocyanin were determined from the result of copper analysis ;15) the dry weight of the protein was obtained by air-drying at $115^{\circ} \mathrm{C}$ to constant weight. Chlorophyll content analysis of the carrot leaves was performed by the method of Mackinney. ${ }^{16}$ ) Sequential degradation from the N-terminal was performed by a manual Edman procedure ${ }^{17}$ ) and solid-phase analysis. ${ }^{18)}$

Results and discussion. Daucus plastocyanin was easily solubilized from the chloroplasts by freezing-thawing and homogenizing the leaves with solid K-phosphate which were dissolved to give $0.2 \mathrm{M}$ K-phosphate buffer, $\mathrm{pH} 7$ in the homogenate. No any increase of the plastocyanin yield was found in an extract from the acetonetreated leaves. The purification procedures described above yield about $10 \mu \mathrm{mol}$ of plastocyanin in the crude extract and about $1.3 \mu \mathrm{mol}$ of purified protein with $\mathrm{A}_{278} / \mathrm{A}_{597}=1.37$ showing a single band by the polvacrylamide electrophoresis. The chlorophylls $a$ of $27.3 \mu \mathrm{mol}$ 
and $b$ of $12 \mu \mathrm{mol}$ were extracted from the fresh carrot leaves of $22.5 \mathrm{~g}$ with $80 \%$ acetone of $360 \mathrm{ml}$. From these results, the ratio of plastocyanin to chlorophyll was found to be $1: 500$. This value is considerably lower than those reported.")

The Daucus cupriplastocyanin showed three broad bands with the respective peaks at 460,597 and $775 \mathrm{~nm}$ (Fig. 1). The absorbance ratio at these peaks was found to be $0.35 / 1.00 / 0.14\left(\mathrm{~A}_{460} / \mathrm{A}_{597} / \mathrm{A}_{775}\right)$. This visible spectrum of cupriplastocyanin completely disappeared upon its reduction with ascorbate, indicating the blue color to be due to a cupric atom in the protein. The protein moiety has a sharp

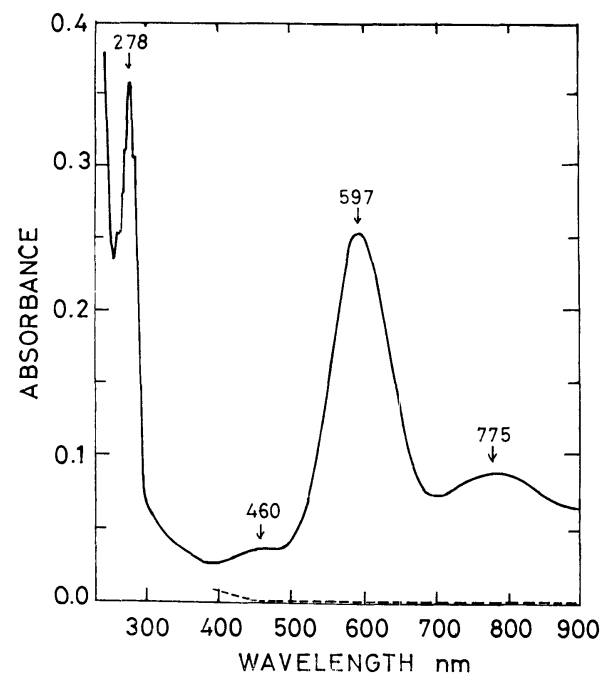

Fig. 1

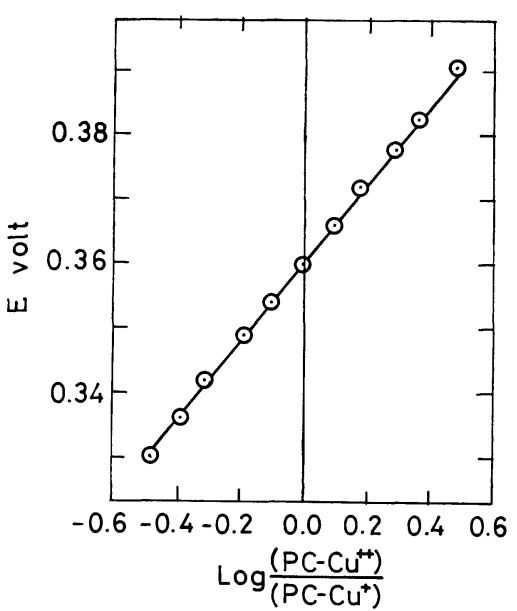

Fig. 2

Figs. 1-2. 1: Absorption spectra of Daucus cupri- and cuproplastocyanin at $20^{\circ} \mathrm{C}$. Cupriplastocyanin $(-)$ was prepared by dialysis against $50 \mu \mathrm{M}$ K-ferricyanide-10 mM K-phosphate buffer, $\mathrm{pH} 7.0$ and cuproplastocyanin (-- ) by adding a minute amount of $\mathrm{Na}$-ascorbate to the cupriplastocyanin solution. 2: Determination of the midpoint redox potential of Daucus plastocyanin with mixtures of $\mathrm{K}$-ferri- and $\mathrm{K}$-ferrocyanide in various ratios in $50 \mathrm{mM}$ K-phosphate buffer, $\mathrm{pH} 7.0$ at $17^{\circ} \mathrm{C}$. Redox reaction of the plastocyanin was followed spectrophotometrically at $597 \mathrm{~nm}$.

ultraviolet band consisting of a main peak at $278 \mathrm{~nm}$ and two fine peaks at 259 and $283.5 \mathrm{~nm}$ and three shoulders at 253, 265 and $269 \mathrm{~nm}$, respectively. These peaks and shoulders at 253, 259, 265 and $269 \mathrm{~nm}$ and the peak at $283.5 \mathrm{~nm}$ are thought to be due to phenylalanine and tyrosine residues, respectively.4) The spectral fine structure of the Daucus plastocyanin is common to those of all higher plant plastocyanins, but not found in some algal plastocyanins.5)

The Daucus plastocyanin did not react with $\mathrm{O}_{2}$ but was readily oxidized with ferricyanide and reduced with ferrocyanide, ascorbate, cysteine or hydrosulfite. The results of titration of the plastocyanin with ferro- and ferricyanide system showed a one-electron change 
and a midpoint redox potential of 0.360 volt for the protein at $17^{\circ} \mathrm{C}$ (Fig. 2). This value is similar to those of several plant plastocyanins $^{5)}$ and cytochrome $f,^{12)}$ but slightly higher than that of algal cytochrome $c_{6} \cdot{ }^{7}$

The molecular weight of Daucus plastocyanin was estimated to be about 12,000 from the result of Sephadex gel filtration. A Daucus plastocyanin solution $(12.0 \mathrm{ml})$ thoroughly dialyzed against water showed $0.512 \mathrm{~cm}^{-1}$ of the absorbance at $597 \mathrm{~nm}$ in cupric state and was found to contain $14.35 \mathrm{mg}$ of the protein and $0.00131 \mathrm{mmol}$ of copper from the results of dry weight and copper analysis. The minimum molecular weight was calculated to be $11 \times 10^{3}$. The millimolar extinction coefficient at $597 \mathrm{~nm}$ was found to be $4.7 \mathrm{mM}^{-1} \cdot \mathrm{cm}^{-1}$. From these results, Daucus plastocyanin was confirmed to be a protein with a molecular weight of about 11,000 containing one copper atom. This value is in good agreement with those obtained by others from amino acid sequence data for several higher plant plastocyanins. ${ }^{\text {) }}$

The N-terminal sequence of the Daucus plastocyanin up to residue 19 was determined by the manual and the solid phase Edman degradation procedures as Ala-Glu-Val-Lys-Leu-Gly-Ala-Asp-AspGly-Ala-Leu-Val-Phe-Ser-Pro-Ser-Ser-Phe. The underlined positions are conserved in the plastocyanins sequenced so far of algae and higher plants. ${ }^{17)}$ It is interesting that Lys-4 is characteristically invariant among the plastocyanins of Apiaceae plants and algae. The amino acid sequence of plastocyanin of the Apiaceae plant is still not completely determined. The complete sequence of the Daucus plastocyanin is now in progress.

Acknowledgements. The authors wish to thank Professor Hideshi Kobayashi, Toho University, and Professor Hiroshi Matsubara, Osaka University, for their valuable advice and encouragement.

\section{References}

1) Katoh, S. (1960): Nature, 186, 533-534.

2) Katoh, S. et al. (1961): Arch. Biochem. Biophys., 94, 136-141.

3) Katoh, S. (1977) : Encycl. Plant Physiol., new ser., 5, 274-252.

4) Katoh, S. et al. (1962): J. Biochem., 51,32-40.

5) Boulter, D. et al. (1977): International Review of Biochemistry, Plant Biochemistry. II (ed. Northcote, D. H.). vol. 13, University Park Press, Baltimore, pp. 1-40.

6) Coleman, P. M. et al. (1978) : Nature, 272, 319-324.

7) Sugimura, Y. et al. (1980): Plant \& Cell Physiol., 21, 1491-1503.

8) Sugimura, Y. et al. (1981): J. Biochem., 90, 1213-1219.

9) Yoshizaki, F. et al. (1981): ibid., 89, 1533-1539.

10) Main, R. K. (1956) : J. Am. Chem. Soc., 81, 6490-6495.

11) Davis, B. J. (1964) : Ann. N. Y. Acad. Sci., 121, 404-427.

12) Davenport, H. E., and Hill, R. (1952): Proc. Roy. Soc., ser. B, 139, 327-345.

13) Sugimura. Y., and Yakushiji, E. (1968) : J. Biochem., 68, 261-269.

14) O'Reilly, J. E. (1973): Biochim. Biophys. Acta, 292, 509-515.

15) Felsenfeld, G. (1960): Arch. Biochem. Biophys., 87, 241-251.

16) Mackinney, G. (1940) : J. Biol. Chem., 132, 91-109.

17) Boulter, D. et al. (1979) : Phytochemistry, 18, 603-608. 